Mhüнан

Rolo Brith

Finm 5 ins

ArthlopubMotra

Fint
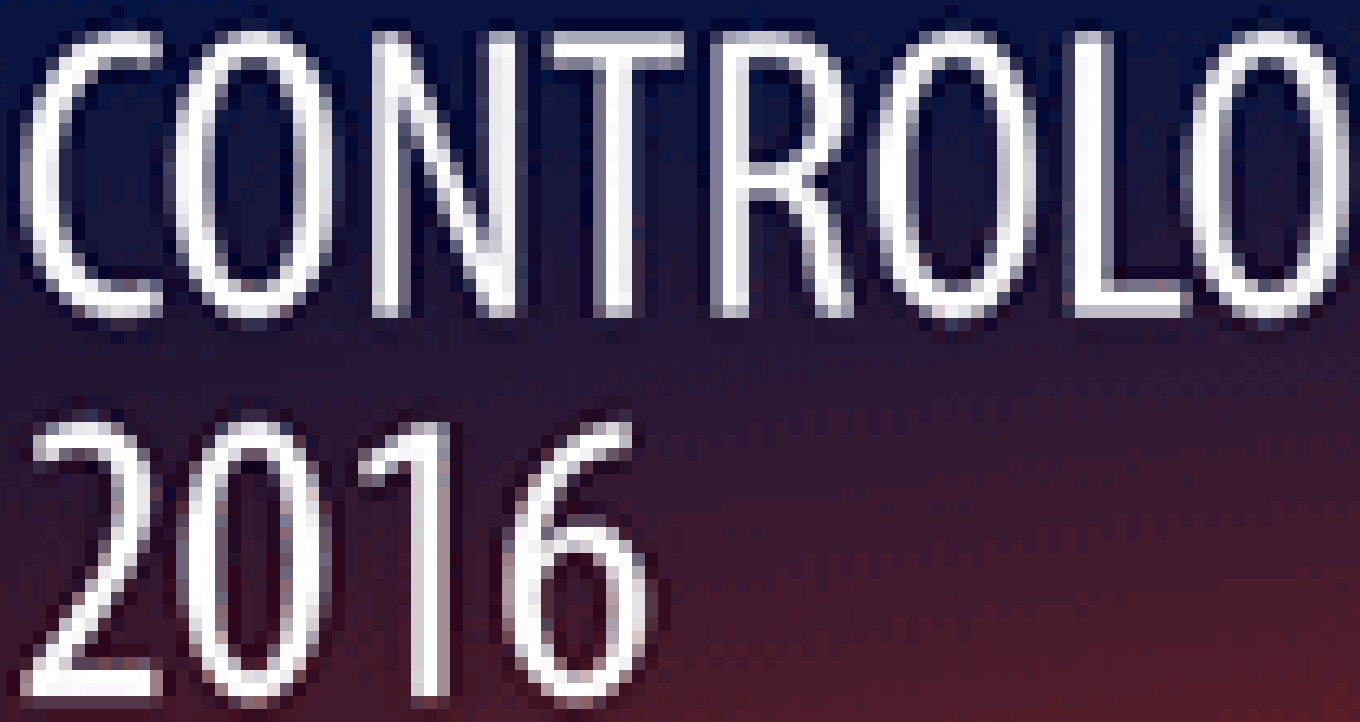

Phos ny of the 1hth Pofucse

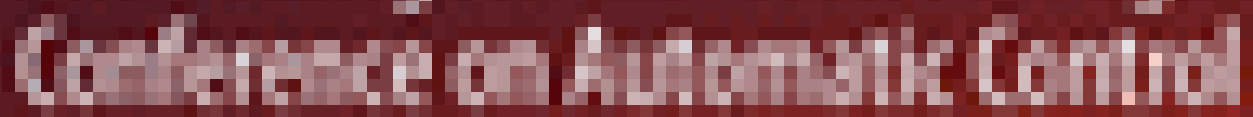




\title{
Milling Parameters Optimization for Surface Quality
}

\author{
Tânia Dias, Nuno Paulo, Luís Queijo, Hernâni Reis Lopes, \\ Manuel Braz César and João Eduardo Ribeiro
}

\begin{abstract}
The Taguchi method is a powerful tool to experiment design optimization and is used in this work to optimize the cutting parameters, which reduce the chatter effect on surface quality. The present study includes feed per tooth, cutting speed, radial and axial depth of cut as control factors. An orthogonal array of L16 was used with the ANOVA analyses in order to identify the significant factors associated to the surface roughness and chatter vibration in three different directions. The optimal cutting combination for the surface finishing was determined through the analysis of surface roughness. This are correlated with the vibrations levels recorded during the experimental tests. The study was carry-out by machining a hardened steel block with tungsten carbide coated tools. The results led to the minimum of arithmetic mean surface roughness of $1.05 \mu \mathrm{m}$ which corresponded to a minimum of the mean vibration level.
\end{abstract}

Keywords Milling - Chatter vibrations - Surface roughness - Taguchi method

\section{Introduction}

The global economy brings growth of manufacturing corporation's competitiveness. For this reason, the machining industrial companies search for higher productivity, production systems flexibility, cost reduction and better surface and dimensional quality. However, these goals only can be reached if the manufacturing parameters are well defined and controlled, and also are dependable of the machine condition and selecting the adequate material and geometry tool. The understanding

T. Dias (更) - N. Paulo · L. Queijo · M.B. César · J.E. Ribeiro

Polytechnic Institute of Bragança, ESTIG/IPB, C. Sta. Apolónia,

5301-857 Bragança, Portugal

e-mail: jribeiro@ipb.pt

H.R. Lopes

Polytechnic Institute of Porto, DEM/ISEP, R. Dr. António Bernardino de Almeida, 4200-072 Porto, Portugal

(C) Springer International Publishing Switzerland 2017

P. Garrido et al. (eds.), CONTROLO 2016, Lecture Notes

in Electrical Engineering 402, DOI 10.1007/978-3-319-43671-5_49 
of metal cutting fundamentals has become essential in last decades to reach the best machining results. However, this is not an easy task due to the complexity of the chip formation mechanism. Modern tendencies of machining are focused online monitoring and control of the machining process, thought the use of sensors and computers. Numerous types of sensors and signal processing techniques have been developed for the direct or indirect diagnosis of aspects, such as the workpiece condition like integrity, surface roughness, dimensional accuracy, the detection of tool wear and breakage, the identification of chatter and analysis of machine component conditions. In spite of all these developments, chatter vibration has been a constraint to improve the productivity and the quality when using metal removal processes [1].

The chatter can occur in most of metal removal processes, namely in turning $[2,3]$, milling $[4,5]$, drilling $[6,7]$, grinding $[8,9]$, boring $[10,11]$ and broaching $[12,13]$. Chatter is classified in two different categories: primary and secondary. The primary, chatter is produced by the cutting process like, i.e. the friction between the tool and the workpiece [14], thermo-mechanical effects on the chip development [15] or by mode coupling $[16,17]$. In secondary category, chatter can be caused by waviness regeneration of the workpiece surface. The effect of regeneration is the most significant cause of chatter and, for because of that, some authors associated the term chatter to phenomena regenerative chatter.

The influence of the chatter in the machining is usually negative effect, causing poor surface quality, machine tool damage, excessive noise, unacceptable inaccuracies, reduced material removal rate etc. Many research works are focus in the characterization of chatter influence as negative effects like in producing low surface quality [18, 19], excessive tool wear [20] or reduced material removal rate $[21,22]$. They measured the vibration during the machining in order to estimate the produced surface roughness, tool life and Material Removal Rate.

In the propose work, the authors implemented a design of experiments using the Taguchi method [23] to determine the optimal parameters in order to obtain the lowest surface roughness. This are correlated with vibration levels measured during the experimental tests.

\section{Design of Experiments and Experimentation}

A specially designed orthogonal array of Taguchi, presented in Table 1, is used to study the effects of the milling parameters through a small number of experiments, allowing a reduction in the time required for all experimental work. The design of experiments is shown with four columns, corresponding of two levels of cutting speed, feed rate, radial depth cut and axial depth cut.

The experimental tests were performed through a machining operation of face milling around a cylindrical workpiece under dry conditions, which were conduced according to design of experiments defined by the orthogonal array L16. The initial dimensions of workpiece were $200 \mathrm{~mm}$ of diameter and $200 \mathrm{~mm}$ of height. 
Table 1 Design of experiment (orthogonal array)

\begin{tabular}{l|l|l|l|l}
\hline Test No. & $\begin{array}{l}\text { A cutting speed } \\
(\mathrm{m} / \mathrm{min})\end{array}$ & $\begin{array}{l}\text { B feed rate } \\
(\mathrm{mm} / \text { tooth })\end{array}$ & $\begin{array}{l}\text { C radial depth cut } \\
(\mathrm{mm})\end{array}$ & $\begin{array}{l}\text { D axial depth cut } \\
(\mathrm{mm})\end{array}$ \\
\hline 1 & 200 & 0.1 & 1 & 0.1 \\
\hline 2 & 200 & 0.1 & 1 & 0.35 \\
\hline 3 & 200 & 0.1 & 2 & 0.1 \\
\hline 4 & 200 & 0.1 & 2 & 0.35 \\
\hline 5 & 200 & 0.3 & 1 & 0.1 \\
\hline 6 & 200 & 0.3 & 1 & 0.35 \\
\hline 7 & 200 & 0.3 & 2 & 0.1 \\
\hline 8 & 200 & 0.3 & 2 & 0.35 \\
\hline 9 & 300 & 0.1 & 1 & 0.1 \\
\hline 10 & 300 & 0.1 & 1 & 0.35 \\
\hline 11 & 300 & 0.1 & 2 & 0.1 \\
\hline 12 & 300 & 0.1 & 2 & 0.35 \\
\hline 13 & 300 & 0.3 & 1 & 0.1 \\
\hline 14 & 300 & 0.3 & 1 & 0.35 \\
\hline 15 & 300 & 0.3 & 2 & 0.1 \\
\hline 16 & 300 & 0.3 & 2 & 0.35 \\
\hline
\end{tabular}

The material of the cylinder was obtained from mould steel GMTC 1.2738 with a hardness of 45 Rockwell C.

The tests were carried out on a vertical machining center, Deckel Maho DMC $63 \mathrm{~V}$, using WC coated tools. The tool inserts were WNHU 04T310, manufactured by Palbit ${ }^{\circledast}$. The milling operations was performed using circular path and around the cylinder perimeter, until reaching the $50 \mathrm{~mm}$ of depth (Fig. 1).

(a)

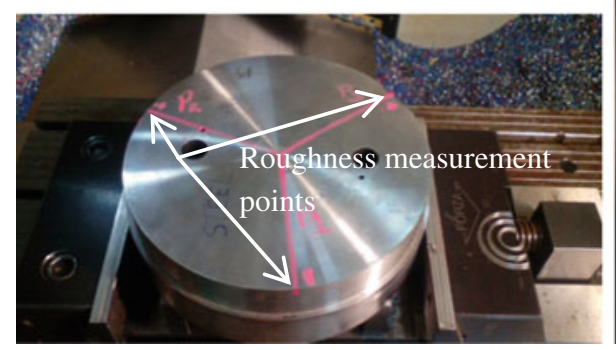

(b)

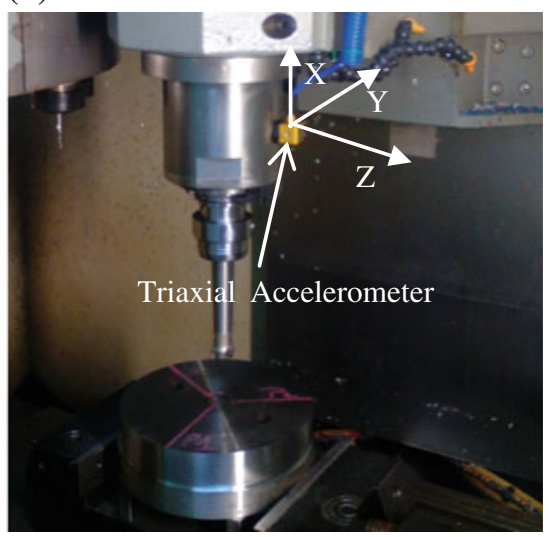

Fig. 1 Workpiece on the milling machine table: a details of roughness measurement points. a and b $3 \mathrm{D}$ accelerometer 
For the present study, was used the $\mathrm{R}_{\mathrm{a}}$ parameter. The Mitutoyo SJ-301 Portable Surface Roughness Tester was used for the measurement of surface roughness along of cylinder axial direction and in three equidistance orientations separate by $120^{\circ}$ angle (P1, P2, P3), see Fig. 1a. For each orientation were taken five measurements, being the lowest and the highest result neglected. Final average $R_{a}$ value is taken by considering the average value of the whole measurements on the three directions.

For the acquisition of chatter vibration produced during the milling tests, a triaxial accelerometer (PCB Piezotronics, model 356B18) was placed on the center of the spindle milling (Fig. 1b). The signal was processed using a vibration signal acquisition USB NI-4431 and post-processed. The RMS and the absolute maximum vibration values were extracted from the measurement and later used for control.

\section{Results}

In Table 3 is represented the results obtained for the experimental tests. The arithmetic mean roughness presented is the mean of the measurements on the three positions, see Fig. 1a. The RMS vibration levels were computed by considering the entire signal recorded during each test, being their values for the three sensor directions, which corresponds to $\mathrm{X}, \mathrm{Y}$ and $\mathrm{Z}$ directions in Fig. 1b, presented in Table 3.

Analyzing the Table 3 is possible verify that the combination of parameters which cause the low value of mean surface roughness, $\bar{R}_{a}$ equal to $1.05 \mu \mathrm{m}$, are the cutting feed of $300 \mathrm{~m} / \mathrm{min}$, feed rate of $0.1 \mathrm{~mm} / \mathrm{tooth}$, radial depth cut of $2 \mathrm{~mm}$ and axial depth cut of $0.35 \mathrm{~mm}$ (test number 12). However, another parameters combination (teste number 1) gives a mean surface roughness value very low, $1.06 \mu \mathrm{m}$, and for that case, the cutting feed was $200 \mathrm{~m} / \mathrm{min}$, the feed rate is $0.1 \mathrm{~mm} /$ tooth, the radial depth cut is $1 \mathrm{~mm}$ and axial depth cut of $0.1 \mathrm{~mm}$.

The vibration analysis is based in RMS values obtained from measurements made with the triaxial accelerometer. From Table 3 is possible to observe that the combination of milling parameters which caused the lowest values of vibration for the three directions is the correspondent to test number 12, cutting feed of $300 \mathrm{~m} / \mathrm{min}$, feed rate of $0.1 \mathrm{~mm} /$ tooth, radial depth cut of $2 \mathrm{~mm}$ and axial depth cut of $0.35 \mathrm{~mm}$. In this case, vibration levels for the $\mathrm{X}, \mathrm{Y}$ and $\mathrm{Z}$ directions were $1.944 \mathrm{~m} / \mathrm{s}^{2}, 1.949 \mathrm{~m} / \mathrm{s}^{2}$ and $5.818 \mathrm{~m} / \mathrm{s}^{2}$, respectively, having Euclidean norm of $3.237 \mathrm{~m} / \mathrm{s}^{2}$. As mentioned above, the lowest value of $R_{a}$ occurred also for the same test number 12. (Table 2).

Another observation about the vibration level is the difference between the average values of each direction, the average value for $X$ direction is $4.316 \mathrm{~m} / \mathrm{s}^{2}, \mathrm{Y}$ direction is $4.386 \mathrm{~m} / \mathrm{s}^{2}$ and for $\mathrm{Z}$ direction is $9.999 \mathrm{~m} / \mathrm{s}^{2}$. In other words, the average values for the $\mathrm{X}$ and $\mathrm{Y}$ are very close while for the $\mathrm{Z}$ has an average value 
Table 2 Experimental results of surface roughness and vibration level of workpiece

\begin{tabular}{l|l|l|l|l|l|l|l|l|c}
\hline Test No. & $\begin{array}{l}\text { A } \\
(\mathrm{m} / \mathrm{min})\end{array}$ & $\begin{array}{l}\mathrm{B} \\
(\mathrm{mm} / \text { tooth })\end{array}$ & $\begin{array}{l}\mathrm{C} \\
(\mathrm{mm})\end{array}$ & $\begin{array}{l}\mathrm{D} \\
(\mathrm{mm})\end{array}$ & $\begin{array}{l}\overline{\mathrm{R}}_{\mathrm{a}} \\
(\mu \mathrm{m})\end{array}$ & $\begin{array}{l}\mathrm{RMS}_{\mathrm{X}} \\
\left(\mathrm{m} / \mathrm{s}^{2}\right)\end{array}$ & $\begin{array}{l}\mathrm{RMS}_{\mathrm{Y}} \\
\left(\mathrm{m} / \mathrm{s}^{2}\right.\end{array}$ & $\begin{array}{l}\mathrm{RMS}_{Z} \\
\left(\mathrm{~m} / \mathrm{s}^{2}\right)\end{array}$ & $\begin{array}{l}\overline{\mathrm{RMS}} \\
\left(\mathrm{m} / \mathrm{s}^{2}\right)\end{array}$ \\
\hline 1 & 200 & 0.1 & 1 & 0.1 & 1.06 & 3.692 & 3.698 & 8.810 & 5.400 \\
\hline 2 & 200 & 0.1 & 1 & 0.35 & 1.61 & 4.774 & 5.043 & 9.238 & 6.352 \\
\hline 4 & 200 & 0.1 & 2 & 0.1 & 3.84 & 4.187 & 3.902 & 9.012 & 5.700 \\
\hline 5 & 200 & 0.1 & 2 & 0.35 & 4.07 & 4.077 & 4.301 & 8.834 & 5.737 \\
\hline 6 & 200 & 0.3 & 1 & 0.1 & 1.30 & 4.104 & 4.154 & 10.279 & 6.179 \\
\hline 7 & 200 & 0.3 & 1 & 0.35 & 2.36 & 5.211 & 5.419 & 12.226 & 7.619 \\
\hline 8 & 200 & 0.3 & 2 & 0.1 & 3.67 & 4.860 & 4.815 & 7.417 & 5.682 \\
\hline 9 & 200 & 0.3 & 2 & 0.35 & 2.63 & 8.776 & 10.146 & 9.089 & 9.337 \\
\hline 10 & 300 & 0.1 & 1 & 0.1 & 1.26 & 9.169 & 10.432 & 17.133 & 12.245 \\
\hline 11 & 300 & 0.1 & 1 & 0.35 & 3.72 & 3.078 & 2.777 & 8.591 & 4.815 \\
\hline 12 & 300 & 0.1 & 2 & 0.1 & 2.54 & 2.737 & 2.301 & 5.841 & 3.626 \\
\hline 13 & 300 & 0.1 & 2 & 0.35 & 1.05 & 1.944 & 1.949 & 5.817 & 3.237 \\
\hline 14 & 300 & 0.3 & 1 & 0.1 & 1.10 & 3.111 & 2.686 & 8.136 & 4.644 \\
\hline 15 & 300 & 0.3 & 1 & 0.35 & 1.32 & 3.212 & 2.849 & 9.018 & 5.026 \\
\hline 16 & 300 & 0.3 & 2 & 0.1 & 3.04 & 3.504 & 3.090 & 8.640 & 5.078 \\
\hline
\end{tabular}

that is more than twice of the others. However, the RMS in the Z direction is not important for the chatter vibration and for that reason will not appear in the following analysis.

\section{Data Analysis and Discussion}

The Taguchi analysis procedure can be described in three steps. In the first, is implemented the evaluation signal-to-noise ratio $(\mathrm{S} / \mathrm{N})$ and allows to define the level of variation for each parameter. This is followed by a comparison of each evaluate characteristic ( $\mathrm{R}_{\mathrm{a}}$ and RMS) among all the tests. The third is based on analysis of variance, which is used to define the influence of each parameter [23].

The $\mathrm{S} / \mathrm{N}$ defined by Taguchi is a measure of robustness used to identify control factors, which decrease the variability in a process by minimizing the effects of uncontrollable factors or noise factors. In the Taguchi designed experiment, is possible to influence the noise factors and forcing the occurrence of variability. From the results, it is identified the optimal control factor that make the process robust or resilient to variation from the noise factors. Higher values of the $\mathrm{S} / \mathrm{N}$ recognize control factor settings that minimize the effects of the noise factors. Taguchi considered three categories of the performance characteristic in the analysis of the S/N [23], namely: nominal is the best, larger is the better and smaller is the better. The follow equations define mathematically the used category in this work. 
Table 3 Tests results and $\mathrm{S} / \mathrm{N}$ ratio for the arithmetic mean roughness

\begin{tabular}{l|l|l|l}
\hline \multirow{2}{*}{ Test No. } & \multirow{2}{*}{$\mathrm{R}_{\mathrm{a}} \mathrm{S} / \mathrm{N}_{\mathrm{s}}(\mathrm{dB})$} & \multicolumn{2}{l}{$\mathrm{RMS}$ vibration } \\
\cline { 3 - 4 } & & \multicolumn{2}{l}{$\mathrm{S} / \mathrm{N}_{\mathrm{s}}(\mathrm{dB})$} \\
\cline { 3 - 4 } & & $\mathrm{X}$ & $\mathrm{Y}$ \\
\hline 1 & -0.517 & -11.37 & -11.38 \\
\hline 2 & -4.301 & -13.64 & -14.12 \\
\hline 3 & -11.699 & -12.44 & -11.83 \\
\hline 4 & -12.215 & -12.21 & -12.70 \\
\hline 5 & -2.356 & -12.29 & -12.43 \\
\hline 6 & -7.483 & -14.45 & -14.81 \\
\hline 7 & -11.335 & -13.78 & -13.69 \\
\hline 8 & -8.501 & -18.87 & -20.13 \\
\hline 9 & -2.008 & -19.26 & -20.37 \\
\hline 10 & -11.455 & -9.77 & -8.89 \\
\hline 12 & -8.192 & -8.75 & -7.24 \\
\hline 13 & -0.436 & -5.86 & -5.83 \\
\hline 14 & -0.860 & -9.86 & -8.59 \\
\hline 16 & -2.460 & -10.14 & -9.10 \\
\hline
\end{tabular}

Smaller is the better (minimize)

$$
S / N_{S}=-10 \times \log \left(\frac{1}{n} \sum_{i=1}^{n} y_{i}^{2}\right)
$$

where $y_{i}$ is the observed data and $n$ is the number of observations.

For present work the $\mathrm{S} / \mathrm{N}$ category used for the surface roughness and for chatter vibration was the "smaller is the better" because the goal is to minimize the roughness on workpiece surface and the tool vibration.

By analyzing the Table 3 , is possible verify that the highest value of $\mathrm{S} / \mathrm{N}_{\mathrm{s}}$ ratio for $\mathrm{R}_{\mathrm{a}}$ occur for the test number 12 and is $-0.436 \mathrm{~dB}$, this meaning that value corresponds to the smaller variance of the output characteristic around the desired value.

In the Table 3 are also presented the of $S / N_{s}$ ratio values for $\mathrm{RMS}$ vibration determined in the three measurement directions. In this case the highest value of $\mathrm{S} / \mathrm{N}_{\mathrm{s}}$ ratio for RMS vibration occur also for the test number 12 with an average value for the three directions of $-9.03 \mathrm{~dB}$ and better value is in the $\mathrm{Y}$ direction $(-5.83 \mathrm{~dB})$. 


\subsection{Analysis of the Signal-to-Noise Ratio}

The signal term in the Taguchi method represents the wanted value (mean) for the output attribute and the noise represents unwanted square deviation value for the output attribute. Thus, $\mathrm{S} / \mathrm{N}$ ratio is the ratio of the mean to the square deviation. The $\mathrm{S} / \mathrm{N}$ ratio is used by Taguchi to measure the quality attribute or characteristic from the wanted value. The smaller $\mathrm{S} / \mathrm{N}$, the better category is applied with the objective of minimizing the surface roughness and chatter vibration. The results of $\mathrm{S} / \mathrm{N}$ for the sixteen combinations (L16) are presented in Table 3. Their analyses allow to split the effect of each cutting parameter for the different levels. The mean $\mathrm{S} / \mathrm{N}$ ratio for each cutting parameter at levels 1 and 2 can be computed by averaging the $S / N$ ratios for correspondent experiments. The mean of $\mathrm{S} / \mathrm{N}$ ratio for each level of cutting parameters are presented in Tables 4 and 5, common defined as the mean $\mathrm{S} / \mathrm{N}$ ratio response table for $\mathrm{Ra}$ and $\mathrm{RMS}$ vibration. The total mean of $\mathrm{S} / \mathrm{N}$ ratio for $R_{a}$ is $-6.232 \mathrm{~dB}$, being the vibration for the $\mathrm{X}$ direction $-12.103 \mathrm{~dB}$ and $\mathrm{Y}$ direction $-11.830 \mathrm{~dB}$.

In the Tables 4 and 5 are shown the $\mathrm{S} / \mathrm{N}$ ratio response graph for roughness and vibration, respectively. One gets a high $\mathrm{S} / \mathrm{N}$ ratio for smaller variance of surface roughness and vibration level around the desired value. Nevertheless, the relative importance among the milling parameters for the surface roughness still required to be identified so optimal combinations of the milling parameter levels can be determine more accurately using an ANOVA analysis.

The optimal cutting parameters are the levels with the highest value of the mean $\mathrm{S} / \mathrm{N}$ ratio for each parameter. In Table 4 is presented the mean $\mathrm{S} / \mathrm{N}$ ratio values for $\mathrm{R}_{\mathrm{a}}$ and is possible to conclude that the combination of optimal parameters is A2B2C1D1. Another observation that can be done is the variation of mean $\mathrm{S} / \mathrm{N}$ ratio for each parameter, thus, $\mathrm{C}$ parameter (radial depth cut) suffer the highest variation $(4.604 \mathrm{~dB})$, which denote a very important influence in the surface quality. In contrast, the variation of level for B parameter (feed rate), cause the lowest difference in the mean $\mathrm{S} / \mathrm{N}$ ratio $(0.265 \mathrm{~dB})$.

From Table 5 one sees that the optimal combination of parameters are the same for vibration in $\mathrm{X}$ and $\mathrm{Y}$ directions $\left(\mathrm{RMS}_{\mathrm{X}}\right.$ and $\left.\mathrm{RMS}_{\mathrm{Y}}\right), \mathrm{A} 2 \mathrm{~B} 1 \mathrm{C} 2 \mathrm{D} 2$.

Table 4 Response table mean $\mathrm{S} / \mathrm{N}$ ratio for $\mathrm{R}_{\mathrm{a}}$ factor and significant interaction

\begin{tabular}{l|l|l|l|l}
\hline Symbol & Cutting parameters & \multicolumn{3}{|l}{ Mean S/N ratio (dB) } \\
\cline { 3 - 5 } & & Level 1 & Level 2 & Max-min \\
\hline A & $\begin{array}{l}\text { Cutting speed } \\
(\mathrm{m} / \mathrm{min})\end{array}$ & -7.301 & -5.163 & 2.138 \\
\hline $\mathrm{B}$ & $\begin{array}{l}\text { Feed rate } \\
(\mathrm{mm} / \text { tooth })\end{array}$ & -6.364 & -6.099 & 0.265 \\
\hline $\mathrm{C}$ & $\begin{array}{l}\text { Radial depth cut } \\
(\mathrm{mm})\end{array}$ & -3.930 & -8.534 & 4.604 \\
\hline $\mathrm{D}$ & $\begin{array}{l}\text { Axial depth cut } \\
(\mathrm{mm})\end{array}$ & -5.828 & -6.636 & 0.808 \\
\hline
\end{tabular}


Table 5 Response table mean S/N ratio for RMS vibration factor and significant interaction

\begin{tabular}{l|l|l|l|l|l}
\hline \multirow{2}{*}{ Symbol } & Cutting parameters & Direction & \multicolumn{3}{|l}{ Mean S/N ratio (dB) } \\
\cline { 4 - 6 } & & & Level 1 & Level 2 & Max-min \\
\hline A & Cutting speed (m/min) & $\mathrm{X}$ & -13.629 & -10.576 & 3.053 \\
\cline { 3 - 6 } & & $\mathrm{Y}$ & -13.885 & -9.775 & 4.110 \\
\hline \multirow{2}{*}{$\mathrm{B}$} & \multirow{2}{*}{ Feed rate $(\mathrm{mm} /$ tooth) } & $\mathrm{X}$ & -11.661 & -12.544 & 0.883 \\
\cline { 3 - 6 } & & $\mathrm{Y}$ & -11.546 & -12.114 & 0.568 \\
\hline C & Radial depth cut $(\mathrm{mm})$ & $\mathrm{X}$ & -12.596 & -11.610 & 0.986 \\
\cline { 3 - 6 } & & $\mathrm{Y}$ & -12.460 & -11.200 & 1.260 \\
\hline D & Axial depth cut $(\mathrm{mm})$ & $\mathrm{X}$ & -12.329 & -11.876 & 0.453 \\
\cline { 3 - 6 } & & $\mathrm{Y}$ & -11.915 & -11.745 & 0.170 \\
\hline
\end{tabular}

The S/N ratio of the RMS vibration can be analyzed by looking at Table 5 . The cutting speed (parameter $\mathrm{A}$ ) is the most influent parameter in the vibration levels for the three directions. Indeed, the maximum mean $\mathrm{S} / \mathrm{N}$ ratio variation occurs for $\mathrm{Y}$ direction $\left(\mathrm{RMS}_{\mathrm{Y}}\right)$ and has the value of $4.110 \mathrm{~dB}$.

\subsection{Analysis of Variance}

The goal of the variance analysis is to determine which design parameters affect meaningfully the surface roughness and chatter vibration. The results of variance of each cutting parameter and their interactions are shown in Tables 6, 7, 8 and 9.

The F-Ratio test is a statistic tool to verify which design parameters affect significantly in the quality characteristic. This is defined as the ratio of the mean squared deviations to the mean squared error. Generally, when show a value greater

Table 6 ANOVA results for surface roughness

\begin{tabular}{l|l|r|l|l|l}
\hline Source & $\begin{array}{l}\text { Degrees of } \\
\text { freedom }\end{array}$ & $\begin{array}{l}\text { Sum of } \\
\text { squares }\end{array}$ & $\begin{array}{l}\text { Mean } \\
\text { squares }\end{array}$ & F-ratio & $\begin{array}{l}\text { Contribution } \\
(\%)\end{array}$ \\
\hline $\mathrm{A}$ & 1 & 18.287 & 18.287 & 1.27 & 6.4 \\
\hline $\mathrm{B}$ & 1 & 0.281 & 0.281 & 0.02 & 0.1 \\
\hline $\mathrm{C}$ & 1 & 84.772 & 84.772 & 5.9 & 29.6 \\
\hline $\mathrm{D}$ & 1 & 2.612 & 2.612 & 0.18 & 0.9 \\
\hline $\mathrm{A} \times \mathrm{B}$ & 1 & 1.002 & 1.002 & 0.07 & 0.4 \\
\hline $\mathrm{A} \times \mathrm{C}$ & 1 & 28.505 & 28.505 & 1.99 & 10.0 \\
\hline $\mathrm{A} \times \mathrm{D}$ & 1 & 2.822 & 2.822 & 0.2 & 1.0 \\
\hline $\mathrm{B} \times \mathrm{C}$ & 1 & 4.124 & 4.124 & 0.29 & 1.4 \\
\hline $\mathrm{B} \times \mathrm{D}$ & 1 & 2.029 & 2.029 & 0.14 & 0.7 \\
\hline $\mathrm{C} \times \mathrm{D}$ & 1 & 69.938 & 69.938 & 4.87 & 24.4 \\
\hline Residual & 5 & 71.800 & 14.360 & & 25.1 \\
\hline Total & 15 & 286.171 & 18.287 & & 100.0 \\
\hline
\end{tabular}


Table 7 ANOVA results for vibration in X-direction $\left(\mathrm{RMS}_{\mathrm{X}}\right)$ and $\mathrm{Y}$-direction $\left(\mathrm{RMS}_{\mathrm{Y}}\right)$

\begin{tabular}{l|l|l|l|l|l}
\hline Source & $\begin{array}{l}\text { Degrees } \\
\text { freedom }\end{array}$ & Sum of squares & Mean squares & F-ratio & $\begin{array}{l}\text { Contribution } \\
(\%)\end{array}$ \\
\cline { 2 - 6 } & $\mathrm{X}-\mathrm{Y}$ & $\mathrm{X}-\mathrm{Y}$ & $\mathrm{X}-\mathrm{Y}$ & $\mathrm{X}-\mathrm{Y}$ & $\mathrm{X}-\mathrm{Y}$ \\
\hline $\mathrm{A}$ & 1 & $37.297-67.560$ & $37.297-67.560$ & $9.02-10.33$ & $20.9-25.9$ \\
\hline $\mathrm{B}$ & 1 & $3.121-1.292$ & $3.121-1.292$ & $0.76-0.20$ & $1.7-0.5$ \\
\hline $\mathrm{C}$ & 1 & $3.890-6.355$ & $3.889-6.355$ & $0.94-0.97$ & $2.2-2.4$ \\
\hline $\mathrm{D}$ & 1 & $0.820-0.116$ & $0.820-0.116$ & $0.20-0.02$ & $0.5-0.0$ \\
\hline $\mathrm{A} \times \mathrm{B}$ & 1 & $9.620-19.156$ & $9.620-19.156$ & $2.33-2.93$ & $5.4-7.4$ \\
\hline $\mathrm{A} \times \mathrm{C}$ & 1 & $22.562-28.406$ & $22.562-28.406$ & $5.46-4.34$ & $12.6-10.9$ \\
\hline $\mathrm{A} \times \mathrm{D}$ & 1 & $30.784-42.999$ & $30.784-42.999$ & $7.45-6.57$ & $17.2-16.5$ \\
\hline $\mathrm{B} \times \mathrm{C}$ & 1 & $29.330-36.723$ & $29.330-36.723$ & $7.10-5.62$ & $16.4-14.1$ \\
\hline $\mathrm{B} \times \mathrm{D}$ & 1 & $18.203-18.397$ & $18.203-18.397$ & $4.40-2.81$ & $10.2-7.1$ \\
\hline $\mathrm{C} \times \mathrm{D}$ & 1 & $2.205-6.670$ & $2.205-6.670$ & $0.53-1.02$ & $1.2-2.6$ \\
\hline Residual & 5 & $20.664-32.699$ & $4.133-6.540$ & & $11.6-12.6$ \\
\hline Total & 15 & $178.496-260.372$ & & & $100.0-100.0$ \\
\hline
\end{tabular}

than four, it means the variation of the design or cutting parameter has an important effect in the quality characteristic.

In this study was determined the contribution of each machining parameter and their interaction. The analysis of the F-Ratio values reveals that more significant factors are the radial depth cut and the interaction between radial depth cut and axial depth cut for minimize the surface roughness. They have contributions about $30 \%$ and $24 \%$, respectively, as can be seen in Table 6 . The optimal cutting parameters for the surface roughness are the cutting speed of level 2, the feed rate of level 2, the radial depth of cut of level 1 and the axial depth of cut of level 1 .

From Table 7 is possible to verify that the most important contributions for minimize the tool vibration in $\mathrm{X}$ direction. The cutting speed, the interaction between the cutting speed and the axial depth of cut, and the interaction between the feed rate and the radial depth of cut are the more significant factors with a contribution of almost $21 \%, 17 \%, 16 \%$, respectively.

The Table 7 shows the contribution of each milling parameter and their interaction for RMS vibration value in Y direction. Is observed that the cutting speed, the interaction between the cutting speed and the axial depth of cut, and the interaction between the feed rate and the radial depth of cut have contribution of $26 \%, 17 \%, 14 \%$, respectively. For the $\mathrm{X}$ and $\mathrm{Y}$ directions, the optimal cutting parameters to minimize the chatter vibration are the cutting speed of level 2, the feed rate of level 1, the radial depth of cut of level 2 and the axial depth of cut of level 2 . 


\section{Conclusions}

The application of the parameter design of the Taguchi method in the optimization of milling operations is presented. The following conclusions can be drawn based on the experimental results of this study:

Taguchi show to be very robust method and allows to improve the surface roughness and minimized the chatter vibration phenomenon.

For a specific range of parameters, the experimental results from the Taguchi method and ANOVA analysis, was possible to identify the test 12 , with a cutting speed of $300 \mathrm{~m} / \mathrm{min}$, the feed rate of $0.1 \mathrm{~mm} / \mathrm{t}$, the radial depth of cut of $2 \mathrm{~mm}$ and the axial depth of cut of $0.35 \mathrm{~mm}$, as the best cutting parameters, leading to average surface roughness of $1.05 \mu \mathrm{m}$ and average RMS vibration of $3.237 \mathrm{~m} / \mathrm{s}^{2}$.

From the ANOVA analysis, we could identify the most influent parameters for surface average roughness and root mean square. For the $\mathrm{R}_{\mathrm{a}}$ the most influent parameter is the radial depth cut with a contribution of $30 \%$. In relation to the vibration, this will dependent on the direction. Therefore, in $\mathrm{X}$ and $\mathrm{Y}$ direction the radial depth cut is the most significant factor, having a contribution of $21 \%$ and $26 \%$, respectively.

This study proved the importance of the interactions between some cutting parameters. The interactions significance is clearly visible in the ANOVA and for both analysis: surface roughness and chatter vibration.

It is verified a relevant relation between the surface roughness and the chatter vibration. It was observed that the parameters combination that leads to the lower roughness is the same for the lower value of RMS vibration values.

\section{References}

1. Quintana, G., Ciurana, J.: Chatter in machining processes: a review. Int. J. Mach. Tools Manuf 51(5), 363-376 (2011)

2. Sadek, M.M.: Stability of centre lathes in orthogonal cutting. Int. J. Prod. Res. 12(5), 547-560 (1974)

3. Devillez, A., Dudzinski, D.: Tool vibration detection with eddy current sensors in machining process and computation of stability lobes using fuzzy classifiers. Mech. Syst. Signal Process. 21(1), 441-456 (2007)

4. Ahmadi, K., Ismail, F.: Machining chatter in flank milling. Int. J. Mach. Tools Manuf. 50(1), 75-85 (2010)

5. Dombovari, Z., Altintas, Y., Stepan, G.: The effect of serration on mechanics and stability of milling cutters. Int. J. Mach. Tools Manuf 50(6), 511-520 (2010)

6. Roukema, J.C., Altintas, Y.: Time domain simulation of torsional-axial vibrations in drilling. Int. J. Mach. Tools Manuf 46(15), 2073-2085 (2006)

7. Mehrabadi, I.M., Nouri, M., Madoliat, R.: Investigating chatter vibration in deep drilling, including process damping and the gyroscopic effect. Int. J. Mach. Tools Manuf. 49(12-13), 939-946 (2009)

8. Hassui, A., Diniz, A.E.: Correlating surface roughness and vibration on plunge cylindrical grinding of steel. Int. J. Mach. Tools Manuf. 43, 855-862 (2003) 
9. Gradisek, J., Baus, A., Govekar, E., Klocke, F., Grabec, I.: Automatic chatter detection in grinding. Int. J. Mach. Tools Manuf. 43(14), 1397-1403 (2003)

10. Atabey, F., Lazoglu, I., Altintas, Y.: Mechanics of boring processes-part I. Int. J. Mach. Tools Manuf. 43(5), 463-476 (2003)

11. Moetakef-Imani, B., Yussefian, N.Z.: Dynamic simulation of boring process. Int. J. Mach. Tools Manuf. 49(14), 1096-1103 (2009)

12. Axinte, D.A., Gindy, N., Fox, K., Unanue, I.: Process monitoring to assist the workpiece surface quality in machining. Int. J. Mach. Tools Manuf. 44(10), 1091-1108 (2004)

13. Axinte, D.A.: An experimental analysis of damped coupled vibrations in broaching. Int. J. Mach. Tools Manuf. 47(14), 2182-2188 (2007)

14. Wiercigroch, M., Krivtsov, A.M.: Frictional chatter in orthogonal metal cutting. Philos. Trans.: Math. Phys. Eng. Sci. (Series A) 359(1781), 713-738 (2001)

15. Wiercigroch, M., Budak, E.: Sources of nonlinearities, chatter generation and suppression in metal cutting. Philos. Trans. Royal Soc. Lond. 359, 663-693264 (2001)

16. Tobias, S.A.: Machine Tools Vibrations. Wiley, New York (1965)

17. Tlusty, J., Polacek, M.: The stability of machine tools against self-excited vibrations in machining. Int. Res. Product. Eng. 465-474 (1963)

18. Jang, D.Y., Choi, Y., Kim, H., Hsiao, A.: Study of the correlation between surface roughness and cutting vibrations to develop an on-line roughness measuring technique in hard turning. Int. J. Mach. Tools Manuf. 36(4), 453-464 (1996)

19. Chen, J., Fang, Q., Lib, P.: Effect of grinding wheel spindle vibration on surface roughness and subsurface damage in brittle material grinding. Int. J. Mach. Tools Manuf. 91, 12-23 (2015)

20. Rao, K.V., Murthy, B.S.N., Rao, N.M.: Prediction of cutting tool wear, surface roughness and vibration of work piece in boring of AISI 316 steel with artificial neural network. Measurement 51, 63-70 (2014)

21. Budak, E., Tekeli, A.: Maximizing chatter free material removal rate in milling through optimal selection of axial and radial depth of cut Pairs. CIRP Ann. Manuf. Technol. 54(1), 353-356 (2005)

22. Tang, W.X., Song, Q.H., Yu, S.Q., Sun, S.S., Li, B.B., Du, B., Ai, X.: Prediction of chatter stability in high-speed finishing end milling considering multi-mode dynamics. J. Mater. Process. Technol. 209(5), 2585-2591 (2009)

23. Ross, P.J.: Taguchi Techniques for Quality Engineering, 2nd edn. McGraw-Hill, New York (1996) 